\title{
Composition of Follow-Up Formula for Young Children Aged 12-36 Months: Recommendations of an International Expert Group Coordinated by the Nutrition Association of Thailand and the Early Nutrition Academy
}

\author{
Umaporn Suthutvoravut $^{\mathrm{a}}$ Philip Olayele Abiodun $^{\mathrm{d}}$ Sirinuch Chomtho ${ }^{\mathrm{b}}$ \\ Nalinee Chongviriyaphan ${ }^{a}$ Sylvia Cruchet ${ }^{e}$ Peter S.W. Davies ${ }^{f}$ George J. Fuchs $^{g}$ \\ Sarath Gopalan ${ }^{i}$ Johannes B. van Goudoever ${ }^{j}$ Etienne de la Rey Nelk \\ Ann Scheimann ${ }^{\mathrm{h}}$ Jose Vicente Spolidoro' Kraisid Tontisirin ${ }^{c}$ Weiping Wang $^{\mathrm{m}}$ \\ Pattanee Winichagoon $^{c}$ Berthold Koletzko ${ }^{n}$ \\ ${ }^{a}$ Department of Pediatrics, Faculty of Medicine Ramathibodi Hospital, Mahidol University, ${ }^{b}$ Department of Pediatrics, \\ Faculty of Medicine, Chulalongkorn University, Bangkok, 'Institute of Nutrition, Mahidol University, Nakhon Pathom, \\ Thailand; d Department of Child Health, School of Medicine, University of Benin, Benin City, Nigeria; ${ }^{\mathrm{e}}$ Institute of \\ Nutrition and Food Technology (INTA), University of Chile, Santiago de Chile, Chile; ${ }^{f}$ Children's Nutrition Research \\ Centre, Queensland Children's Medical Research Institute, University of Queensland, Queensland, Australia; \\ ${ }^{9}$ Department of Pediatrics/Gastroenterology Section, University of Arkansas for Medical Sciences, Little Rock, Ark., \\ ${ }^{h}$ Division of Pediatric Gastroenterology and Nutrition, Johns Hopkins University School of Medicine, Baltimore, Md., \\ USA; 'Nutrition Foundation of India, New Delhi, India; 'Department of Pediatrics, Emma Children's Hospital, Academic \\ Medical Center, and VU University Medical Center, Amsterdam, Netherlands; ${ }^{k}$ Department of Paediatrics and Child \\ Health, Faculty of Medicine and Health Sciences, Stellenbosch University, Cape Town, South Africa; 'School of \\ Medicine, Pontificia Universidade Católica do Rio Grande do Sul, Porto Alegre, Brazil; ${ }^{\mathrm{m}}$ Shanghai Medical College of \\ Fudan University, Shanghai, PR China; ' Ludwig-Maximilians-University of Munich, Dr. von Hauner Children's Hospital, \\ Munich, Germany
}

\section{Key Words}

Young child feeding · Food standards · Follow-up formula · Nutritional requirements

\section{Abstract \\ Background: There are no internationally agreed recom- mendations on compositional requirements of follow-up formula for young children (FUF-YC) aged 1-3 years. Aim: The aim of the study is to propose international composi-}

tional recommendations for FUF-YC. Methods: Compositional recommendations for FUF-YC were devised by expert consensus based on a detailed literature review of nutrient intakes and unmet needs in children aged 12-36 months. Results and Conclusions: Problematic nutrients with often inadequate intakes are the vitamins $A, D, B 12, C$ and folate, calcium, iron, iodine and zinc. If used, FUF-YC should be fed along with an age-appropriate mixed diet, usually contributing $1-2$ cups (200-400 ml) of FUF-YC daily (approximately $15 \%$ of total energy intake). Protein from cow's milk-based

\section{KARGER 125}

(C) 2015 S. Karger AG, Basel

0250-6807/15/0672-0119\$39.50/0

E-Mail karger@karger.com

www.karger.com/anm
Dr. Umaporn Suthutvoravut

Department of Pediatrics, Faculty of Medicine Ramathibodi Hospital

Mahidol University, 270 Rama 6 Road

Bangkok 10400 (Thailand)

E-Mail u.suthut@gmail.com 
formula should provide $1.6-2.7 \mathrm{~g} / 100 \mathrm{kcal}$. Fat content should be 4.4-6.0 g/100 kcal. Carbohydrate should contribute $9-14 \mathrm{~g} / 100 \mathrm{kcal}$ with $>50 \%$ from lactose. If other sugars are added, they should not exceed $10 \%$ of total carbohydrates. Calcium should provide $200 \mathrm{mg} / 100 \mathrm{kcal}$. Other micronutrient contents $/ 100 \mathrm{kcal}$ should reach $15 \%$ of the World Health Organization/Food and Agriculture Organization recommended nutrient intake values. A guidance upper level that was 3-5 times of the minimum level was established. Countries may adapt compositional requirements, considering recommended nutrient intakes, habitual diets, nutritional status and existence of micronutrient programs to ensure adequacy while preventing excessive intakes.

(c) 2015 S. Karger AG, Basel

\section{Introduction}

The aim of this position paper is to provide recommendations on the composition of follow-up formula for young children (FUF-YC) aged 1-3 years. These recommendations were developed by an international expert group based on a review of available information on dietary nutrient intakes and their comparison with reference nutrient intakes (RNIs) to identify problematic nutrients for which reference intakes often are not achieved in this age group.

During the first 3 years of life, children have high requirements of both macro and micronutrients to support their fast growth and development of organs, including the brain. The World Health Organization (WHO) recommends, as a global public health recommendation, that infants be exclusively breastfed for the first 6 months of life to achieve optimal growth, development and health, based on a systematic review that was published in 2001 and updated in 2009 [1]. WHO advises the continuation of partial breastfeeding during the second half of infancy and for up to 2 years of age or beyond, along with the provision of nutritionally adequate and safe complementary foods [2]. Locally produced foods should be used whenever feasible. The age of 12-36 months is a period of transition from breastfeeding combined with complementary feeding to consuming a variety of regular family foods, with a greater risk of inadequate nutrient supply as compared to the age of full breastfeeding or older ages. Young children around the world, particularly those in developing countries as well as those in disadvantaged groups in all countries, are prone to developing nutrient deficiencies and growth faltering due to inadequate amounts and/or poor quality of complementary feeding and family foods, often aggravated by high infection rates.

In the early 1990s, various agencies, particularly the UN agencies and national governments, aimed at harmonizing their efforts in improving child nutrition. Victora et al. [3] used data from the Demographic and Health Survey from 54 low to middle income countries to examine the patterns of growth faltering in various geographical regions of the world. In both Africa and Southeast Asia, faltering in weight and height was observed from approximately 6 months of age onwards and continued through 24 months. Declines in height or length were more drastic than in weight, and the degree of faltering in these 2 regions was worse than in other regions of the world.

Improvements regarding the prevalence of all forms of undernutrition (i.e. stunting, wasting and underweight) have been reached [4]. Although the global target of reducing stunting in young children may not be fully met by 2025 , a significant reduction has been reached in various countries. Meanwhile, the rapid rise in prevalence of childhood overweight and obesity worldwide has resulted in a dual burden of malnutrition in several countries dealing with high rates of both under and overnutrition. Micronutrient deficiencies of public health importance, such as vitamin A, iron and iodine deficiencies, remain a major challenge. While iron deficiency (ID) was the main cause of anemia in Europe, it contributed to a smaller percentage of anemia in Asia and Africa. While 63\% of young child anemia in Europe was corrected by iron supplementation, only $34 \%$ was corrected in Africa and even less (18\%) in Southeast Asia [4]. Hence, iron interventions alone will not completely eradicate anemia in these 2 regions where the problem of anemia has been more severe relative to other regions of the world. Other than the 3 micronutrient deficiencies mentioned above, deficiencies in zinc, folate, vitamin B12 and, recently, vitamin D have emerged as potential public health concerns.

When children do not achieve adequate nutrient intake from eating normal foods, fortified foods and nutrient supplements including formula products should be considered to complement locally available foods for satisfying nutritional requirements [5].

Formula products for children aged 1-3 years have been marketed and used in many countries for about 2 decades [6]. Information on nutrient contents in 244 FUF-YC marketed in the European Union has been published [7]. In 1987, the Codex Alimentarius Commission adopted a standard for follow-up formula (FUF) for in- 
fants from the 6th month and for young children [8], which is currently under review [9]. However, there are no internationally agreed definitions and compositional requirements for FUF-YC. Such products have been called 'growing up milks', 'growing up formulas' or 'toddlers' milk'. We propose not using the term 'growing up' in the name of products or the product category because no specific effect on growth has been shown. Also, we favor not using the term 'milk' because such formulas are not necessarily based on animal milk but may also be based on plant protein sources. Therefore, the term 'follow-up formula for young children' (FUF-YC) is preferred.

In 2013, the European Food Safety Authority (EFSA) concluded that FUF-YC is one of several means to increase intakes of critical nutrients in young children wherever inadequate intakes are common, along with the possible contribution from other sources, such as fortified cow's milk, fortified cereals and cereal-based foods, supplements or the regular consumption of meat and fish [10]. This expert group supports the conclusion that FUF-YC does not have a unique role in providing critical nutrients to young children, and it therefore cannot be considered an irreplaceable necessity to satisfy the nutritional requirements of young children. However, this expert group agrees that FUF-YC with an appropriate composition under appropriate conditions of use can provide a major and valuable contribution toward improving the supply of critical nutrients, overall nutritional status and hence help to support child health. In this context, we provide, here, the recommendations for the appropriate composition of FUF-YC.

Recommendations on the composition of fortified foods are based on data on nutrient intakes and on nutritional needs of the target population. In 2013, EFSA published an evaluation of the nutrient requirements and the dietary intakes of infants and young children in the European Union, to inform their review of infant formula and FUF for ages of 0-36 months. Although the EFSA review identifies key nutrients which are either inadequate or excessive throughout Europe, there are only limited data on nutrient intakes outside of Europe [10]. Subsequently, EFSA released a scientific opinion on the compositional requirements of infant formula and of FUF for infants aged 6-12 months [11]. A recommendation with a global perspective on the compositional requirements of FUF for use in infancy (6-12 months) was published by an international expert group coordinated by the Early Nutrition Academy (ENA), which also recommended that the compositional requirements of formula products for young children aged 12-36 months should be further considered [12].

Therefore, the Nutrition Association of Thailand (NAT) under the Patronage of Her Royal Highness Princess Maha Chakri Sirindhorn, in collaboration with the ENA and the Federation of International Societies on Pediatric Gastroenterology, Hepatology and Nutrition (FISPGHAN), agreed to coordinate the development of recommendations on the composition of FUF-YC with a global perspective, based on a review on nutritional requirements and dietary intakes for young children worldwide.

\section{Methods}

NAT and ENA coordinated the review and issued a call for qualified experts, which was circulated throughout the FISPGHAN and its member societies in Asia-Pacific, Europe, North America and South America. Proposals for experts from Africa, Asia, Asia-Pacific, Europe, North America and South America were submitted to NAT. Experts were then selected from the nominations based on having documented expertise, skills and experience to be able to contribute the required knowledge for the task and its objectives. The participating experts (cf. list of authors) were asked to review and evaluate the results about the detailed literature reviews performed by NAT and to attend an Expert Meeting on the 'Compositional considerations of formula products for young children aged 12-36 months' held in Bangkok on 30 April and 1 May, 2014.

A working group of the NAT (N.C., P.W. and S.C.) performed a review of global data on nutrient intakes of young children aged 12-36 months and on dietary intake. A systematic search of peer-reviewed English language articles in PubMed from 2004 onwards was conducted during February 2014 using the keywords: 'nutrient or dietary or diet' and 'intake' and 'infant or toddler or preschool'. The strategy was followed to perform a systematic literature search for a period of 10 years (2004-2014) and to hand search key references of previously published papers cited in detected publications. The electronic literature search identified 5,020 publications of potential relevance. From 5,020 articles, the working group selected those performed as either national surveys or cross-sectional community-based surveys, that included children aged 12-36 months. Gray literature sources consisting of government reports of national surveys were also included. The nutrient intake data were collected using food records, 24-hour food recalls and/or food frequency questionnaires, and then converted into nutrient intakes using computerized softwares. After the screening of titles, abstracts and full texts, 23 publications from 19 countries were included in the review.

The expert group reviewed the dietary intake reference values for young children aged 12-36 months and decided that the WHO/ FAO reports on protein, energy and most vitamin and mineral RNI values [13-16] were the most appropriate references for assessing the adequacy of dietary intakes for the current project. An exception was made for vitamin $\mathrm{D}$ which was based on the average 
given by the US Institute of Medicine of the National Academies (IOM; $15 \mu \mathrm{g} /$ day) and by the WHO/FAO RNI ( $5 \mu \mathrm{g} /$ day) values.

Taking into consideration the data on nutritional status and dietary intakes, the expert group identified those nutrients that are most often limited in the diets of children aged 12-36 months. Recommendations for the composition of FUF-YC were based on the assumption that these products should provide approximately $15 \%$ of a child's energy requirement. Minimum values for micronutrients were established for those nutrients that were identified as problematic.

\section{Nutrient Intakes and Status of Young Children Aged 12-36 Months}

Data on nutrient intakes and biochemical status in young children aged 12-36 months from 19 countries were reviewed by the expert group [17-41]. They are obtained from both national surveys and cross-sectional community-based surveys in Asia (Bangladesh, India, Indonesia, Malaysia, People's Republic ofChina, Philippines, Thailand and Vietnam), Australia, New Zealand, Europe (France, Ireland and Norway), Africa (Cameroon and South Africa), North America (Canada, Mexico and USA) and South America (Brazil). Reports that included the amount of nutrient intakes in the population of interest were found in 17 countries (mentioned above except Cameroon and South Africa). Nutrients in those reports include carbohydrate, fat, protein, calcium, iron, zinc, vitamins A, B1, B2, B12, C, D, E and folate. Data on energy intake were available from all 17 countries. However, data were not always available for all nutrients or for the specific 12-36 month age group in all surveys. For example, a report from China showed energy intakes of children aged 12-36 months, while another from Norway reported energy intakes of infants and children aged 0-24 months. Table 1 lists daily energy and nutrient intakes of young children aged 1236 months by countries.

According to the available data, young children in Bangladesh, China, India and Philippines had a reported mean energy intake of $<800 \mathrm{kcal} / \mathrm{day}$, which is lower than the $\mathrm{FAO} / \mathrm{WHO} / \mathrm{UNU}$ energy intake recommendation of $950-1,125 \mathrm{kcal} /$ day for boys and $850-1,050 \mathrm{kcal} /$ day for girls aged 1-3 years, respectively. Young children in most countries had protein intakes clearly exceeding the recommended intakes, except for Bangladesh where protein intakes were just close to recommendations. In contrast, average daily micronutrient intakes were often much lower than the WHO/FAO RNIs. Among the national surveys in children aged 12-36 months, micronutrient intakes and assessment of adequacy were reported using different criteria. Hence, the magnitude of inadequacy cannot be directly compared across surveys. Further details are provided for those nutrients which could be considered problematic as a result of a large discrepancy between reported intakes and the WHO/FAO RNIs, high prevalence of inadequate intakes or biochemical insufficiency.

\section{Vitamin A}

Vitamin A intakes of young children in Brazil, Mexico, the Philippines and some subgroups of the population in Indonesia were much lower than the WHO/FAO RNIs.

Vitamin A inadequacy was reported in $6.8 \%$ of young children aged 16-24 months in Australia using estimated average requirement (EAR; $210 \mu \mathrm{g}$ retinol equivalent (RE)) as the reference [27], in $81.5 \%$ of those in India according to intake below $50 \%$ of RNI (400 $\mu \mathrm{g}$ RE) [19] and in $50 \%$ of children aged 1-9 years in South Africa concerning the intake less than two-thirds of the RNI $(300 \mu \mathrm{g}$ RE for 1-3 years, $400 \mu \mathrm{g}$ RE for $4-8$ years and $600 \mu \mathrm{g}$ RE for $9-13$ years) [40]. In addition, 44 and $60 \%$ of children aged $0.5-1.9$ and 2-4.9 years, respectively, in Vietnam, had vitamin A intake below the local dietary requirement (400 $\mu \mathrm{g} /$ day) [25]. Similarly, $>50 \%$ of Thai children (in all studied age groups, $0.5-12.9$ years) had low vitamin A intake [24]. In Mexico, vitamin A inadequacy, based on an EAR of $210 \mu \mathrm{g}$ RE, was found in 37.6, 30.5 and $26.7 \%$ of children aged 1, 2 and 3 years, respectively [36]. Using serum retinol concentration for the assessment of vitamin A status, 1.5, 9 and $15.2 \%$ of children in Indonesia [20], New Zealand [29] and Philippines [23], respectively, were found to have insufficient vitamin A (serum or plasma retinol $<0.7 \mu \mathrm{mol} / \mathrm{l}$ or $<20 \mu \mathrm{g} / \mathrm{dl}$ ).

\section{Vitamin B1}

Vitamin B1 intakes of young children aged 12-24 months in Brazil [38] and the Philippines [23] were lower than the WHO/FAO RNIs while those of children from Australia, Canada, France, Ireland, Vietnam and the USA were adequate. Since the problem was limited to only 2 countries, it was not deemed to be of global concern.

\section{Vitamin D}

Using serum 25-hydroxyvitamin D concentration to define status, vitamin D deficiency (serum 25-hydroxyvitamin $\mathrm{D}<27.5 \mathrm{nmol} / \mathrm{l}$ or $<50 \mathrm{nmol} / \mathrm{l}$ ) was found in $10 \%$ of children aged 6-23 months in New Zealand [42], and in 34.9 and $42.8 \%$ of children aged $2-4.9$ years in urban and rural areas of Indonesia, respectively [20]. Nutrient intake data from Brazil found that $92-94 \%$ of children 


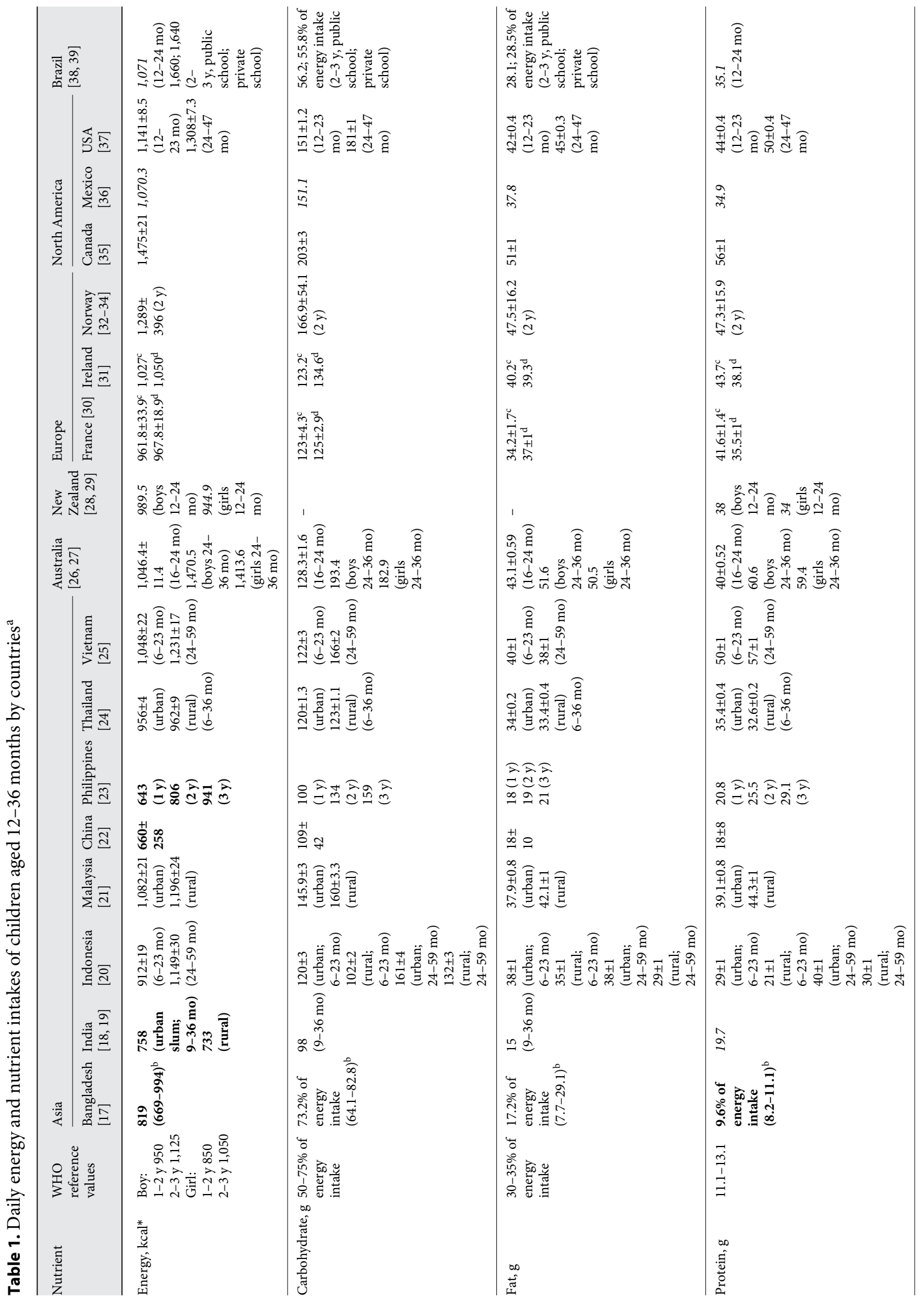




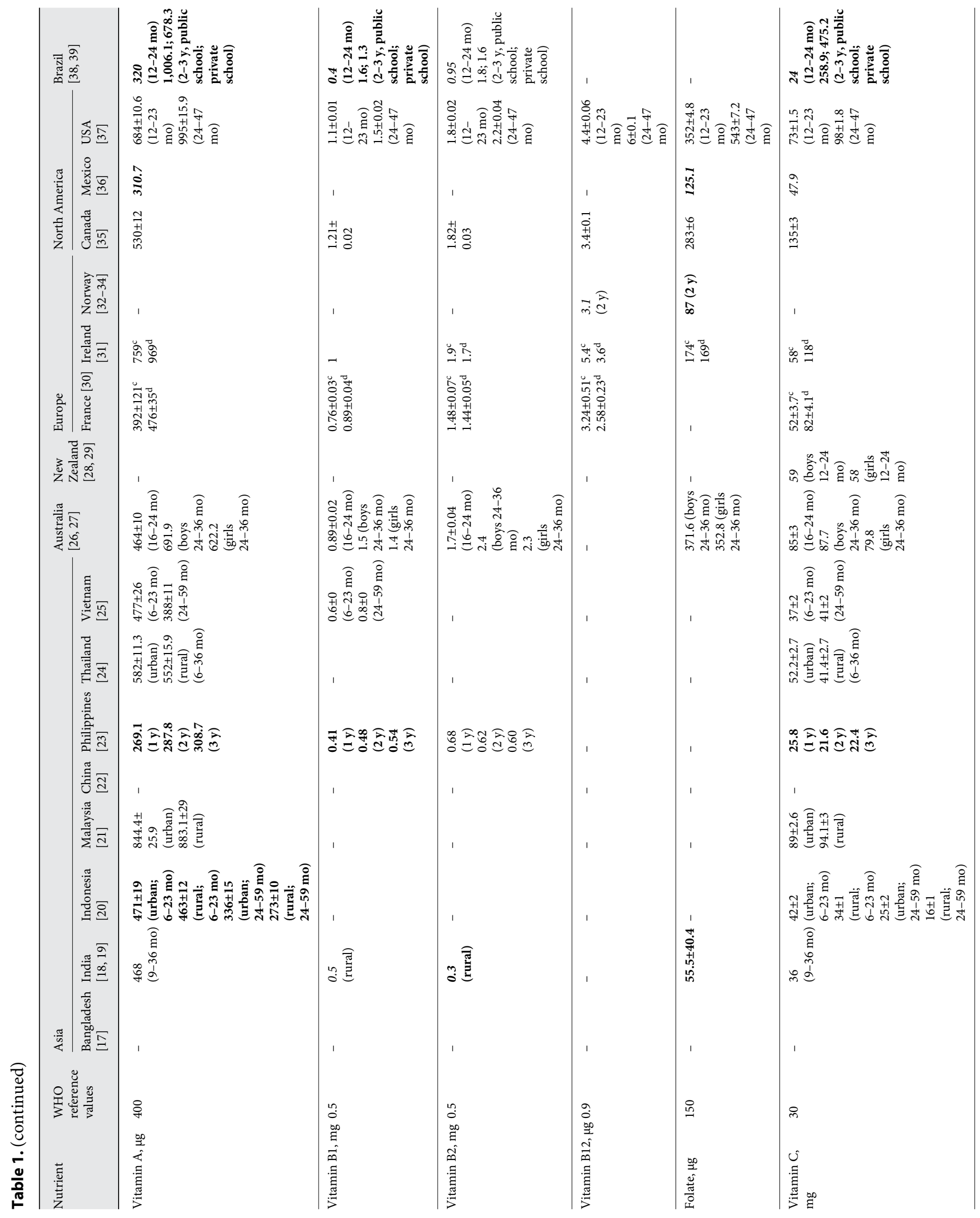




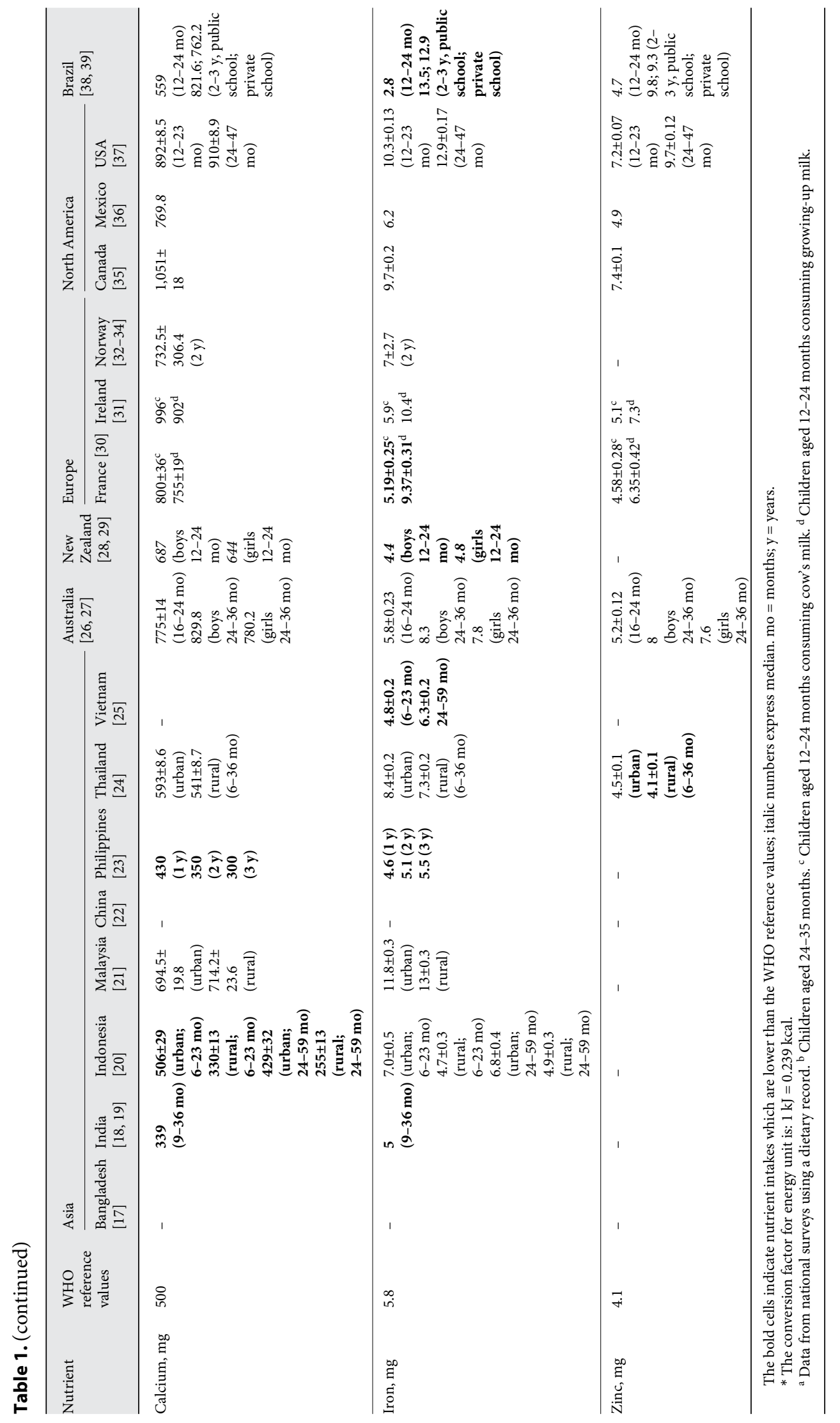


aged 2-3 years had inadequate intakes of vitamin D (EAR of $10 \mu \mathrm{g}$ ) [39]. In a survey from France, all children consuming milk and milk-based products had dietary vitamin D intake below RNI (10 $\mu \mathrm{g} /$ day) while $75 \%$ of those consuming growing-up milk had dietary vitamin $\mathrm{D}$ intake below RNI [30]. In Ireland, a vitamin D intake below EAR ( $10 \mu \mathrm{g} /$ day) was reported in $98 \%$ of children consuming milk and milk-based products and in $69 \%$ of those consuming growing-up milk [31]. It must be recognized that not many foods contain vitamin $\mathrm{D}$, and the food composition database may be incomplete.

Recent surveys in young children from 4 countries in Southeast Asia also showed that vitamin D insufficiency may be a problem in tropical countries [20,24], in addition to countries that are at higher latitudes such as North America $[43,44]$ and Europe [10].

\section{Vitamin B12}

Vitamin B12 deficiency has been reported in those subgroups of the populations with low intake of foods from animal sources due to unavailability or cultural or religious beliefs [45]. Prevalence of vitamin B12 deficiency was approximately $6-9 \%$ in Mexican children aged 1-3 years from the National Health and Nutrition Survey in 2006 [46]. According to a cross-sectional survey in 1997, no Norwegian children aged 2 years had cobalamin intake below RNI (Norwegian RNI of $0.8 \mu$ g or WHO RNI of $0.9 \mu \mathrm{g}$ ) [34].

\section{Folate}

Approximately, $40 \%$ of Indian children aged 1-3 years had an inadequate folate intake $(<50 \%$ of RNI which is $80 \mu \mathrm{g} /$ day). Similarly, $50 \%$ of children aged $1-9$ years in South Africa had a folate intake less than two-thirds of the RNI (150 $\mu \mathrm{g} /$ day) [40]. In Mexico, food records revealed that $43-58 \%$ of children aged $1-3$ years had insufficient folate intake [36]. Another study from Mexico showed, by biochemical assessment, that only $0.7-8 \%$ of children aged 1-3 years had folate insufficiency [46]. In Norway, folate intake below the recommended level $(80 \mu \mathrm{g} /$ day $)$ was found in $35 \%$ of children aged 2 years although only $5.8 \%$ of them had low serum folate levels $(<10 \mathrm{nmol} / \mathrm{l})$ [34].

\section{Vitamin C}

Several reports from Asian countries showed low or inadequate vitamin $\mathrm{C}$ intake among young children. Vitamin C intakes in children aged 12-24 months in Brazil [38], in those aged $<5$ years in the Philippines [23] and in some subgroups of the population in Indonesia [20] were much lower than the WHO/FAO RNIs. In India, 76.9\% of children had vitamin C intake of $<50 \%$ that of RNI (40 mg/day) [19]. Similarly, $68-74 \%$ of children aged 1-3 years, in the Philippines had a vitamin $C$ intake of $<80 \%$ of the recommended level (recommended energy and nutrient intake (RENI) of $30 \mathrm{mg} /$ day) [23]. Likewise, $71 \%$ of Vietnamese children, during their first 2 years, had lower than recommended vitamin C intake $(30 \mathrm{mg} /$ day) [25]. In Thailand, over $50 \%$ of children aged $0.5-$ 12.9 years had low vitamin $C$ intake [24]. A similar picture was also observed in other geographical regions. In South Africa, $50 \%$ of children aged 1-9 years had a vitamin C intake of less than two-thirds of RNI (15 mg/day) [40]. Vitamin C insufficiency was reported in $8-12 \%$ of Mexican children aged 1-3 years [36]. In France, $11 \%$ of children consuming growing-up milk formula and $49 \%$ of those consuming milk and milk-based products but not receiving growing-up formula or FUF had vitamin C intake below RNI (60 mg/day) [30]. Lastly, $13.8 \%$ of children aged 16-24 months in Australia had a vitamin C intake below EAR ( $25 \mathrm{mg} /$ day) [27].

\section{Calcium}

In the non-milk-drinking populations, low calcium intake is common. Calcium intakes were lower than RNIs of FAO/WHO for young children in India, Indonesia and Philippines. In the Philippines, $60-80 \%$ of children aged $1-3$ years had calcium intakes below $80 \%$ of RENI ( 500 $\mathrm{mg} /$ day) [23]. In Indonesia, 67 and $78 \%$ of boys and girls aged 18-36 months had calcium intake below RNI (500 $\mathrm{mg}$ /day), respectively. In contrast, in Australia, only 8.3\% of children had calcium intake below EAR (360 mg/day) [27].

\section{Iodine}

Low iodine intake (less than EAR of $65 \mu \mathrm{g} /$ day), based on the 24 -hour dietary recall, was reported in $7 \%$ of children aged 2-3 years in Australia [26]. In New Zealand, the estimation of mean daily exposure to iodine for a toddler group aged $1-3$ years $(47-57 \mu \mathrm{g})$ was below the RNI of $90 \mu \mathrm{g}$ [47]. The 4th Thailand Health Examination Survey during 2008-2009 showed that median urinary iodine concentration of children aged 1-3 years was $>100 \mu \mathrm{g} / \mathrm{l}$, which indicated adequate intakes.

\section{Iron}

Reports from several countries in Asia showed that iron intake among young children aged 1-3 years were generally low. Low iron intakes were reported among young children in Brazil, France, India, New Zealand, Philippines and Vietnam. In Philippines, iron intake of 
$<80 \%$ the RENI ( $8 \mathrm{mg} /$ day) was reported in $69-76 \%$ of children aged 1-3 years [23]. In Indonesia, 71 and $79 \%$ of boys and girls, respectively, aged 2-4.9 years, had an iron intake below RNI (8-10 mg/day) [20]. Over $80 \%$ of Vietnamese children aged 6 months to 3 years had low iron intake [25]. In India, $48.9 \%$ of children aged 1-3 years had an iron intake of $<50 \%$ that of the RNI ( $9 \mathrm{mg}$ /day) [19]. In contrast, only 8.4 and $2.4 \%$ of children in the urban and rural areas of Malaysia, respectively, had iron intake below RNI (6 mg/day) [21]. Almost $60 \%$ of children aged 12-24 months, consuming cow's milk, in France [30] and Ireland [31], had iron intake below RNI or EAR, respectively. Approximately, 23\% of Australian children aged 16-24 months had iron intake below EAR $(4 \mathrm{mg} /$ day) [27]. ID (serum ferritin $<12 \mu \mathrm{g} / \mathrm{l}$ ) and ID anemia were reported in 6.3 and $3.1 \%$, respectively, of children aged 12-24 months in New Zealand. The prevalence of ID and ID anemia were also much more severe in developing countries, for example, 74.3 and $30.8 \%$ in children aged 12-24 months in Brazil.

\section{Zinc}

Due to limited zinc values in most food composition databases, direct assessment of zinc intake is infrequently available. Among 8 countries who reported their dietary zinc intakes, only children in Thailand had low zinc intakes [24]. Low zinc intake was reported in 56\% of French children consuming milk and milk-based products and $33 \%$ of those consuming growing-up milk [30]. In Cameroon, 8 and $9 \%$ of non-breastfeeding children aged 12-59 months had low zinc intake according to the International Zinc Nutrition Consultative Group EAR of $2 \mathrm{mg} /$ day and the IOM EAR of $2.5 \mathrm{mg} /$ day, respectively [41]. Plasma zinc concentration showed that $82.6 \%$ of these children had zinc deficiency (adjusted plasma zinc $<65 \mu \mathrm{g} / \mathrm{dl})$.

Using national food availability and dietary requirement, it was estimated that $17 \%$ of the world's population had inadequate zinc intake, with Asia and Africa being the most affected regions [48].

\section{Docosahexaenoic Acid}

Compared to the adequate intake of docosahexaenoic acid (DHA) for young children of $100 \mathrm{mg} /$ day as defined by EFSA [10], reported intakes were low. A recent national survey from Australia published in 2013 [49] reported very low DHA intakes in Australian children aged $2-3$ years at median value of 3.9 (IQR $0.6-24$ ) $\mathrm{mg}$ /day. In the subgroup of children who ate fish, the energy adjusted intakes of DHA were 16-fold higher (median 50, IQR 25-

Composition of FUF-YC Aged 12-36

Months
$109 \mathrm{mg} / 1,000 \mathrm{kcal} /$ day). The median DHA intake value was much lower than the mean intake of $31.2 \pm 77.2 \mathrm{mg} /$ day, suggesting a skewed data distribution. Likewise, data from the National Health and Nutrition Examination Survey in 1999-2000 for the US population reported the mean intake of DHA around $20 \mathrm{mg} /$ day in children $<6$ years of age [50]. The recent FAO report in 2010 [15] set the Adequate Intake (AI) of DHA for infants aged 6-24 months at $10-12 \mathrm{mg} / \mathrm{kg} /$ day, based on the supply with human milk, under the assumption that human milk provides half of the daily energy needs after 6 months. The values for children aged 2-4 years were the AI of $100-150 \mathrm{mg} /$ day. There is a paucity of DHA intake data from developing countries. A small survey in China reported the mean $( \pm S D)$ DHA intake of toddlers who were 1-3 years, in Yunnan, at $34 \pm 148 \mathrm{mg} /$ day [22], similar to the mean (5th-95th percentile) of $40(10-80) \mathrm{mg} /$ day for thebreastfed toddlers whowere 2-3 years from Bangladesh [51]. For those non-breastfed Bangladeshi children, the reported intake in this age group was much lower at 20 $(0-30) \mathrm{mg} /$ day. The mean DHA intake of Gambian toddlers was $10 \mathrm{mg} /$ day [52].

In summary, from the limited data available, DHA intake of toddlers who were not breastfed and did not eat fish, in both developed and developing countries, were clearly lower than the AI set by different authorities.

\section{Problematic Nutrients}

In summary, the expert group considered the following nutrients to be often limited in the diets of young children, namely vitamins $\mathrm{A}, \mathrm{D}, \mathrm{B} 12, \mathrm{C}$ and folate and calcium, iodine, iron, zinc and DHA.

The results of this review are in agreement with those of several reviews that have assessed those micronutrients which are limited in the diets of young children across various regions.

In the EFSA review of dietary intakes of young children in Europe, average intakes of alpha-linolenic acid (ALA), DHA, iron, vitamin D and iodine, in some European countries, were low compared to recommended intakes [10]. Dietary intakes of protein, salt and potassium are generally high in young children across Europe. Intakes of dietary fiber in young children are low, although not at levels that were considered to be a concern to the EFSA.

Young children, particularly those in developing countries or disadvantaged groups, are prone to nutrient deficiencies due to inadequate and poor quality 
complementary feeding as well as due to infection. In developing countries, the usual problem nutrients are iron and zinc. In children who consume plant-based diets predominantly, the bioavailability of iron and zinc is also lowered. Other nutrients which may be insufficient include the B vitamins (B1, B2, niacin, B6, B12 and folate), vitamins $\mathrm{A}, \mathrm{C}$ and $\mathrm{E}$ and calcium and iodine [53]. Recent reports both by the WHO [5] and the EFSA [10] highlight the need to improve dietary iron supply to older infants and young children and, in some situations, also iodine supply. Neither of the report found issues with reaching protein requirements, but concerns about high intakes were raised.

\section{Proposed Compositional Requirements of FUF-YC Aged 12-36 Months}

This expert group considered that the use of adequately composed FUF-YC is one of several options that can contribute to improving nutrient supply to young children up to the age of 3 years, and thus reduce the prevalence of micronutrient deficiencies. The group based its recommendation on the concept that FUF-YC is not the exclusive source of nutrients but will be fed along with appropriate meals and at times also along with partial breastfeeding. FUF-YC should preferably be consumed as a drink from a cup, not by bottle feeding, to promote desirable eating habits. The recommended number of daily servings is $1-2$ cups $(200-400 \mathrm{ml})$ providing an average consumption of $300 \mathrm{ml} /$ day or approximately $15 \%$ of total energy intake in young children.

The proposed minimum and maximum values of nutrient contents in the formula products are derived from scientific evidence on nutritional requirement and safety in young children. This expert group recognizes the variation of nutrient requirements, dietary intakes and the nutritional status of population groups in different geographical areas. Also, micronutrient supplementation programs vary among different countries and should be considered in setting values for prevention of excessive nutrient intakes. Therefore, the desirable levels of nutrients in FUFYC may differ to some extent among countries. However, nutrient contents per $100 \mathrm{kcal}$ for FUF-YC that are generally considered adequate are presented in table 2 .

\section{Energy Density}

After preparing the FUF-YC according to the manufacturer instruction, it shall contain not $<45 \mathrm{kcal}(190 \mathrm{~kJ})$ and not $>70 \mathrm{kcal}(295 \mathrm{~kJ})$ of energy per $100 \mathrm{ml}$. The min-
Table 2. Proposed compositional requirements of FUF-YC aged 12-36 months

\begin{tabular}{|c|c|c|c|}
\hline Component & Minimum & Maximum & GUL \\
\hline Energy, kcal/100 ml & 45 & 70 & \\
\hline \multicolumn{4}{|l|}{ Proteins, g/100 kcal } \\
\hline Cow's milk protein & 1.6 & 2.7 & \\
\hline Soy protein isolate & 2 & 2.7 & \\
\hline \multicolumn{4}{|l|}{ Lipids } \\
\hline Total fat, g/100 kcal & 4.4 & 6 & \\
\hline $\mathrm{LA}, \mathrm{mg} / 100 \mathrm{kcal}$ & 500 & NS & \\
\hline $\mathrm{ALA}, \mathrm{mg} / 100 \mathrm{kcal}$ & 50 & NS & \\
\hline Trans-fatty acids, $\%$ of fat & NS & 2 & \\
\hline $\mathrm{DHA}^{1}, \%$ of fat & 0.3 & NS & \\
\hline \multicolumn{4}{|l|}{ Carbohydrates, g/100 kcal } \\
\hline Total carbohydrates & 9 & 14 & \\
\hline \multicolumn{4}{|l|}{ Vitamins } \\
\hline Vitamin $\mathrm{A}^{2}, \mu \mathrm{g} \mathrm{RE} / 100 \mathrm{kcal}$ & 60 & & 180 \\
\hline Vitamin D, $\mu \mathrm{g} / 100 \mathrm{kcal}$ & 1.5 & & 4.5 \\
\hline Vitamin $\mathrm{B} 12, \mu \mathrm{g} / 100 \mathrm{kcal}$ & 0.15 & & 0.75 \\
\hline Folic acid, $\mu \mathrm{g} / 100 \mathrm{kcal}$ & 20 & & 100 \\
\hline Vitamin C, mg/100 kcal & 4.5 & & 22.5 \\
\hline \multicolumn{4}{|l|}{ Minerals and trace elements } \\
\hline \multicolumn{4}{|l|}{ Iron $^{3}$ (formula based on cow's milk } \\
\hline $\begin{array}{l}\text { protein), } \mathrm{mg} / 100 \mathrm{kcal} \\
\text { Iron (formula based on soy }\end{array}$ & 1 & & 3 \\
\hline protein isolates), $\mathrm{mg} / 100 \mathrm{kcal}$ & NS & & NS \\
\hline Calcium, mg/100 kcal & 200 & & NS \\
\hline Sodium, mg/100 kcal & 25 & & 75 \\
\hline Iodine, $\mu \mathrm{g} / 100 \mathrm{kcal}$ & 12 & & 36 \\
\hline Zinc, mg/100 kcal & 0.6 & & 1.8 \\
\hline
\end{tabular}

NS = Not specified.

${ }^{1}$ The addition of DHA is optional.

${ }^{2} 1 \mu \mathrm{g} \mathrm{RE}=1 \mu \mathrm{g}$ all-trans retinol $=3.33 \mathrm{IU}$ vitamin A. Retinol contents shall be provided by preformed retinol, while any contents of carotenoids should not be included in the calculation and declaration of vitamin A activity.

${ }^{3}$ The bioavailability is approximately $10 \%$.

imum energy density is similar to fat-reduced cow's milk $(1.6 \mathrm{~g}$ of fat $/ 100 \mathrm{ml})$ which is about $45 \mathrm{kcal} / 100 \mathrm{ml}$. This energy density is appropriate in populations with a generally sufficient energy supply and a significant risk of excessive weight gain and development of obesity. The maximum value is close to the energy content of breast milk, which is about $65 \mathrm{kcal} / 100 \mathrm{ml}$, and which is also the energy content that should be approached in populations of young children with a high prevalence of early childhood growth faltering.

\section{Protein}

The safe level of protein intake for children who are 1-3 years as established by the $\mathrm{WHO} / \mathrm{FAO}$ is about $11-$ $13 \mathrm{~g} /$ day, which is close to the recommendations of the IOM, the EFSA, and the National Health and Medical Re- 
search Council of Australia. Excess protein intakes during infancy and early childhood may enhance weight gain and later risk of obesity [54-56]. High protein intakes that exceed the metabolic requirements can induce higher levels of insulin and insulin-like growth factor-1 (IGF-1), and it can also alter the concentrations of IGF-binding proteins. A high protein supply also increases renal molar solute load and water loss which can increase risk of dehydration when fluid intake is insufficient. A double-blind, randomized clinical trial conducted by the European Childhood Obesity Trial Study Group found that feeding infant formula and FUF with a lower protein content during the first year of life induces a marked health benefit in reducing BMI and obesity risk at school age, as compared to conventional formula with high protein contents [55]. A systematic literature review assessing the health effects of protein intake in infancy and childhood in a Nordic setting revealed that a protein intake between 15 and $20 \%$ of energy intake in early childhood is associated with an increased risk of overweight later in life [56].

The EFSA proposed that the minimum protein content in infant formula and FUF should be $1.8 \mathrm{~g} / 100 \mathrm{kcal}$ for cow's and goat's milk-based formula. This proposal is based on previous studies regarding the adequacy of infant formula containing about $1.8 \mathrm{~g}$ protein $/ 100 \mathrm{kcal}$, but did not take into account the lower protein requirements according to the growing-up age at which FUF is consumed, as compared to early infancy. Given that the review generally identified high protein intakes in young children, and the safe level of intake for protein established by the WHO/FAO/UNU for infants aged 12 months $(1.14 \mathrm{~g} / \mathrm{kg} /$ day $)$ is approximately $6 \%$ of their energy requirement, the expert group proposes that the minimum protein content in the formula products for children aged 12-36 months should be $1.6 \mathrm{~g} / 100 \mathrm{kcal}$, which is around $6 \%$ of energy. The maximum level should be $2.7 \mathrm{~g} / 100 \mathrm{kcal}$, which is around $10 \%$ of energy.

Plant proteins generally have lower amino acid scores and are less digestible than animal proteins. Therefore, when protein sources of FUF-YC are plant proteins, such as soy protein isolate, the minimum protein content has been set at 1.25 times the minimum of cow's milk-based formula, equivalent to $2 \mathrm{~g} / 100 \mathrm{kcal}$, while the maximum value is set at the same level, that is, $2.7 \mathrm{~g} / 100 \mathrm{kcal}$ [12].

For protein sources other than cow's milk and soy protein isolate, the approximate minimum and maximum values should be determined based on scientific evidence, preferably from randomized controlled clinical trials.

Composition of FUF-YC Aged 12-36

Months
The expert group did not provide values for hydrolyzed protein because there is no evidence to support the use of hydrolyzed protein for allergy prevention in early childhood.

\section{Fat}

The recommended total fat content is $4.4-6.0 \mathrm{~g} / 100$ $\mathrm{kcal}$, which is equivalent to about $40-55 \%$ of energy, similar to that in breast milk. FUF-YC should contain essential fatty acids (EFA), that is, linoleic acid (LA, 18:2, n-6) and alpha-linolenic acid (ALA, 18:3, n-3), since dietary EFA intakes are often lower than the recommended level in young children [10]. The minimum values for LA and ALA are 500 and $50 \mathrm{mg} / 100 \mathrm{kcal}$, respectively, which is similar to those proposed for formulas used in infancy by the EFSA [11]. The addition of DHA as an optional ingredient should be permitted, since there are indications of potential benefits of a supply of preformed DHA and intakes are often low in young children [10]. If added, the proposed minimum content of DHA is $15 \mathrm{mg} / 100 \mathrm{kcal}$, equivalent to $0.3 \%$ of total fat, based on the proportion of DHA in human milk which is $0.2-0.5 \%$ (weight percentage) of total fatty acids [11]. Since the FUF-YC is supposed to provide only $15 \%$ of the nutritional requirement (around $200 \mathrm{kcal} /$ day), the toddlers in this age group can and should be encouraged to receive DHA from other food sources. Moreover, they are able to synthesize DHA from its precursor ALA more effectively than those of the younger age or those born preterm. For the same reason, the DHA:AA ratio is not defined since the variation in the DHA and AA intake is dependent on other food sources rather than the FUF-YC alone. The content of trans-fatty acids should be $<2 \%$ that of the total fatty acids, given the potential adverse effects of trans-fatty acids $[57,58]$.

\section{Carbohydrates}

The minimum and maximum values of carbohydrates in the formula products are calculated based on residual energy after the subtraction of minimum and maximum energy from protein and fat contents. The proposed minimum carbohydrate content is $9 \mathrm{~g} / 100 \mathrm{kcal}$ (36\% of energy) while the maximum value is $14 \mathrm{~g} / 100 \mathrm{kcal}$ (56\% of energy).

The main source of carbohydrates should be lactose, which should provide not $<50 \%$ of total carbohydrates, equivalent to $4.5 \mathrm{~g} / 100 \mathrm{kcal}$. For formula with protein from plant source, lactose is not required.

The expert group agreed that there is no need to add sugars other than lactose for nutritional reasons. If addition of sugar is deemed necessary to achieve palatability, 
the content of sugars other than lactose should not exceed $10 \%$ of total carbohydrates or approximately $5 \%$ of total energy content, which is similar to the WHO guideline on added sugar intake for the general population [59].

Other carbohydrates may be added provided that the maximum carbohydrate content is not exceeded. Oligosaccharides, glucose polymers, maltodextrin and precooked or gelatinized starches can be added to provide energy. Non-digestible carbohydrates and fibers that are proven to be suitable for age and safe may be added.

\section{Micronutrients}

Recent national or community-based nutritional surveys of young children found insufficient intakes of many micronutrients in the subgroups of population, both at the country and global level. Problematic vitamins include vitamins A, D, B12, C and folate. The problematic minerals and trace elements include calcium, iodine, iron and zinc. Therefore, the expert group considered it important that minimum contents of these vitamins and minerals should be established for FUF-YC.

The expert group proposes that, except for calcium, the minimum values for $100 \mathrm{kcal}$ are $15 \%$ of the RNI established by the WHO/FAO. The upper values are not based on hard evidence, but on a precautionary principle approach, and thus should be considered as guidance upper levels (GULs). The expert group proposes that a GUL should be set at 3-5 times that established as the minimum level. For those nutrients with high upper tolerable intake levels (ULs) set by the WHO, such as vitamins $\mathrm{C}$ and $\mathrm{B}$ group, the maximum levels should be $75 \%$, and for those nutrients with low UL, such as iron and others, the maximum levels should be $45 \%$ of RNI values. In any case, the maximum nutrient levels should not exceed UL for this age group. Other micronutrients may be added in a certain proportion of RNIs based on evidences of insufficient diet and safety.

\section{Calcium}

Milk and dairy products are good sources of bioavailable calcium in young children. Based on the rationale that drinking an average $300 \mathrm{ml} /$ day of the formula products with the same energy density as whole cow's milk will provide at least a similar amount of calcium as the latter, the proposed minimum value for calcium content is $200 \mathrm{mg} / 100 \mathrm{kcal}$. This value is equivalent to about $40 \%$ of the recommended intake established by the $\mathrm{WHO} /$ FAO (500 mg/day). The maximum value is not established.

\section{Non-Nutrient Components}

Other non-nutrient components such as probiotics and prebiotics may be added based on documented benefits, efficacy and safety. To promote appropriate feeding habits and behavior, artificial flavors should preferably not be added.

\section{Other Aspects}

While the proposed compositional requirements of FUF-YC are based on current scientific information, progress in scientific understanding and food technology may require modification of these conclusions over time. While this expert group considers the use of nutrient fortified products such as FUF-YC beneficial for improving nutritional status, this should not replace the active promotion of appropriate dietary and eating habits of young children including the protection, promotion and support of breastfeeding and appropriate complementary foods.

\section{Acknowledgments}

We gratefully acknowledge the organization of the meeting by the NAT under the Patronage of Her Royal Highness Princess Maha Chakri Sirindhorn. We are grateful to the President of FISPGHAN and the President of ENA for calling in experts to participate in the meeting. We thank Ms. Ploenpit Hanjaroenvanapusit and Mrs. Phinporn Suchanprasurth for their logistic help.

Financial support was provided by the New Zealand Ministry for Primary Industries (MPI) and the Commission of the European Communities, the 7th Framework Programme, contract FP7289346-EARLY NUTRITION. The manuscript does not necessarily reflect the views of the MPI, NAT or the Commission and in no way anticipates future policy in this area.

\section{Disclosure Statement}

U.S. has had scientific and educational collaborations with Nestlé Nutrition, Mead Johnson Nutrition and Dumex. P.O.A. received an honorarium for chairing a scientific session from Wyeth Nutrition. S.C. has had scientific and educational collaborations with Nestlé Nutrition and Mead Johnson Nutrition. N.C. has had scientific and educational collaborations with Nestlé Nutrition, Mead Johnson Nutrition and Dumex. S.C. has had scientific and educational collaborations with Biocodex, Danone, Nestlé Nutrition and Pfizer Nutrition. P.S.W.D.'s research group (The Children's Nutrition Research Centre) has received support from Nestlé Nutrition, Bayer, Nutricia, Pfizer Nutrition, Aspen, Danone Nutrition, Abbott Nutrition and the Infant Nutrition Council. J.B.G. received research grants and speaker fees from various formula companies. He is actively supporting breastfeeding and is a member of the National Breastfeeding Council and the National Nutrition Council in the Netherlands. E.R.N. received a publica- 
tion honorarium from AstraZeneca. A.S. has participated in a clinical research with limited support from Nutricia. W.W. is a member of the Nestlé Nutrition Council, Nestec Ltd. P.W. has had scientific and educational collaborations with Dumex. The Ludwig-Maximilians-University of Munich and its employee B.K. have received support from Abbott Nutrition, Beneo, Danone, Fonterra, Hipp, Mead Johnson Nutrition and Nestlé Nutrition for scientific and educational activities, predominantly as part of pub- lically funded research project with support of the European Commission or German governmental research support. B.K. is a member of the National Breastfeeding Committee and tends to be biased toward breastfeeding. None of the authors report a conflict of interest which would represent 'a set of circumstances that creates a risk that professional judgment or actions regarding a primary interest will be unduly influenced by a secondary interest' as defined by the US Institute of Medicine.

\section{References}

1 Kramer MS, Kakuma R: Optimal duration of exclusive breastfeeding. Cochrane Database Syst Rev 2012;8:CD003517.

2 World Health Organization: Global Strategy for Infant and Young Children Feeding. Geneva, World Health Organization, 2003.

-3 Victora CG, de Onis M, Hallal PC, Blössner M, Shrimpton R: Worldwide timing of growth faltering: revisiting implications for interventions. Pediatrics 2010;125:e473-e480.

-4 Black RE, Victora CG, Walker SP, Bhutta ZA, Christian P, de Onis M, et al; Maternal and Child Nutrition Study Group: Maternal and child undernutrition and overweight in lowincome and middle-income countries. Lancet 2013;382:427-451.

5 WHO Guidelines Approved by the Guidelines Review Committee: Essential Nutrition Actions: Improving Maternal, Newborn, Infant and Young Child Health and Nutrition. Geneva, World Health Organization, 2013.

-6 Przyrembel H, Agostoni C: Growing-up milk: a necessity or marketing? World Rev Nutr Diet 2013;108:49-55.

7 Pérez B, Segarra F, Frontera M, Viadel B: External scientific report. Report of 'data collection with respect to the availability and nutritional composition of different types of milkbased drinks and similar products for young children with the denomination of 'growing up milks' or 'toddlers' milks' or with similar terminology currently on the market in EU member states. EFSA Journal 2013:EN-505.

8 Codex Alimentarius Commission: Codex Standard for Follow-Up Formula. Codex Stan 156-1987. Rome, Codex Alimentarius Commission, 1987.

9 Joint FAO/WHO Food Standards Programme: Proposal to Review the Codex Standard for Follow-Up Formula (Codex Stan 156-1987). Codex Committee on Nutrition and Foods for Special Dietary Uses, ThirtyFourth Session. Bad Soden am Taunus, Germany, 2012.

10 European Food Safety Authority (EFSA): Scientific Opinion on nutrient requirements and dietary intakes of infants and young children in the European Union. EFSA Journal 2013. 11:3408.

11 European Food Safety Authority (EFSA) Panel on Dietetic Products, Nutrition and Allergies (NDA): Scientific opinion on the essen- tial composition of infant and follow-on formulae. EFSA J 2014;12:3760.

12 Koletzko B, Bhutta ZA, Cai W, Cruchet S, El Guindi M, Fuchs GJ, et al: Compositional requirements of follow-up formula for use in infancy: recommendations of an international expert group coordinated by the early nutrition academy. Ann Nutr Metab 2013;62: 44-54.

13 Joint WHO/FAO/UNU Expert Consultation: Protein and amino acid requirements in human nutrition. World Health Organ Tech Rep Ser 2007;935:1-265.

14 FAO/WHO/UNU: Human Energy Requirements: Report of a Joint FAO/WHO/UNU Expert Consultation. Rome, FAO Food and Nutrition Technical Report Series, 2004.

15 FAO: Fats and Fatty Acids in Human Nutrition. Report of An Expert Consultation. Rome, FAO Food and Nutrition, 2010, p 91.

16 World Health Organization, Food and Agricultural Organization of the United Nations: Vitamin and Mineral Requirements in $\mathrm{Hu}$ man Nutrition, ed 2. Geneva, WHO, 2004.

17 Yakes EA, Arsenault JE, Islam MM, Ahmed T, German JB, Drake C, et al: Dietary intake of polyunsaturated fatty acids among breastfeeding and non-breast-feeding 24- to 48month-old children in Bangladesh. J Pediatr Gastroenterol Nutr 2011;52:351-359.

18 Kapur D, Sharma S, Agarwal KN: Dietary intake and growth pattern of children 9-36 months of age in an urban slum in Delhi. Indian Pediatr 2005;42:351-356.

19 National Institute of Nutrition, Indian Council of Medical Research: Diet and Nutritional Status of Rural Population, Prevalence of Hypertension and Diabetes among Adults and Infants and Young Child Feeding Practices. Hyderabad, 2012.

20 Sandjaja S, Budiman B, Harahap H, Ernawati F, Soekatri M, Widodo Y, et al: Food consumption and nutritional and biochemical status of 0.5-12-year-old Indonesian children: the SEANUTS study. Br J Nutr 2013; 110(suppl 3):S11-S20.

21 Poh BK, Ng BK, Siti Haslinda MD, Nik Shanita S, Wong JE, Budin SB, et al: Nutritional status and dietary intakes of children aged 6 months to 12 years: findings of the nutrition survey of malaysian children (SEANUTS Malaysia). Br J Nutr 2013;110(suppl 3):S21-S35.
22 Barbarich BN, Willows ND, Wang L, Clandinin MT: Polyunsaturated fatty acids and anthropometric indices of children in rural China. Eur J Clin Nutr 2006;60:1100-1107.

23 Food and Nutrition Research Institute: Philippines Nutrition: Facts and Figures 2008 (December 2010).

24 Rojroongwasinkul N, Kijboonchoo K, Wimonpeerapattana W, Purttiponthanee S, Yamborisut U, Boonpraderm A, et al: SEANUTS: the nutritional status and dietary intakes of 0.5-12-year-old Thai children. Br J Nutr 2013;110(suppl 3):S36-S44.

25 Le Nguyen BK, Le Thi H, Nguyen Do VA, Tran Thuy N, Nguyen Huu C, Thanh Do T, et al: Double burden of undernutrition and overnutrition in Vietnam in 2011: results of the SEANUTS study in 0.5-11-year-old children. Br J Nutr 2013;110(suppl 3):S45-S56.

262007 Australian National Children's nutrition and physical activity survey: Main findings. Commonwealth of Australia 2008

27 Webb K, Rutishauser I, Knezevic N: Foods, nutrients and portions consumed by a sample of Australian children aged 16-24 months. Nutr Dietetics 2008;65:56-65.

28 Soh P, Ferguson EL, McKenzie JE, Skeaff S, Parnell W, Gibson RS: Dietary intakes of 6-24-month-old urban South Island New Zealand children in relation to biochemical iron status. Public Health Nutr 2002;5:339346.

29 Grant CC, Wall CR, Brunt D, Crengle S, Scragg R: Population prevalence and risk factors for iron deficiency in Auckland, New Zealand. J Paediatr Child Health 2007;43: 532-538.

30 Ghisolfi J, Fantino M, Turck D, de Courcy GP, Vidailhet M: Nutrient intakes of children aged 1-2 years as a function of milk consumption, cows' milk or growing-up milk. Public Health Nutr 2012;16:524-534.

31 Walton J, Flynn A: Nutritional adequacy of diets containing growing up milks or unfortified cow's milk in Irish children (aged 12-24 months). Food Nutr Res 2013;57:21836

32 Kristiansen AL, Laugsand Lillegaard IT, Frost Andersen L: Effect of changes in a food frequency questionnaire: comparing data from two national dietary survey instruments among 12-month-old infants. BMC Public Health 2013;13:680. 
33 Kristiansen AL, Lillegaard IT, Lande B, Andersen LF: Effect of changes in an FFQ: comparing data from two national dietary survey instruments among 2-year-olds. Br J Nutr 2013;109:363-369.

34 Hay G, Trygg K, Whitelaw A, Johnston C, Refsum H: Folate and cobalamin status in relation to diet in healthy 2-y-old children. Am J Clin Nutr 2011;93:727-735.

35 Canadian Community Health Survey: Nutrient Intakes From Food 2008, 2009.

- 36 Mundo-Rosas V, Rodríguez-Ramírez S, Shamah-Levy T: Energy and nutrient intake in Mexican children 1 to 4 years old: results from the Mexican national health and nutrition survey 2006. Salud Publica Mex 2009;51(suppl 4) S530-S539.

-37 Butte NF, Fox MK, Briefel RR, Siega-Riz AM Dwyer JT, Deming DM, Reidy KC: Nutrient intakes of US infants, toddlers, and preschoolers meet or exceed dietary reference intakes. J Am Diet Assoc 2010;110(suppl 12): S27-S37.

- 38 Castro TG, Baraldi LG, Muniz PT, Cardoso MA: Dietary practices and nutritional status of 0-24-month-old children from Brazilian Amazonia. Public Health Nutr 2009;12:23352342.

-39 Bueno MB, Fisberg RM, Maximino P, Rodrigues Gde P, Fisberg M: Nutritional risk among Brazilian children 2 to 6 years old: a multicenter study. Nutrition 2013;29:405-410.

-40 Labadarios D, Steyn NP, Maunder E, MacIntryre U, Gericke G, Swart R, et al: The national food consumption survey (NFCS): South Africa 1999. Public Health Nutr 2005; 8:533-543.

41 Engle-Stone R, Ndjebayi AO, Nankap M, Killilea DW, Brown KH: Stunting prevalence, plasma zinc concentrations, and dietary zinc intakes in a nationally representative sample suggest a high risk of zinc deficiency among women and young children in Cameroon. J Nutr 2014;144:382-391.
42 Grant CC, Wall CR, Crengle S, Scragg R: Vitamin D deficiency in early childhood: prevalent in the sunny South Pacific. Public Health Nutr 2009;12:1893-1901.

43 Yetley EA: Assessing the vitamin D status of the US population. Am J Clin Nutr 2008;88: 558S-564S.

44 Health Canada: Canadian Community Health Survey Cycle 2.2, Nutrition (2004). Nutrient Intakes From Food. Health Canada, Statistics Canada 2009. http://www.hc-sc.gc.ca/fn-an/ surveill/nutrition/commun/art-nutr-childenf-eng.php.

45 de Benoist B: Conclusions of a WHO technical consultation on folate and vitamin B12 deficiencies. Food Nutr Bull 2008;29(suppl): S238-S244.

46 Cuevas-Nasu L, Mundo-Rosas V, ShamahLevy T, Méndez-Gómez Humaran I, AvilaArcos MA, Rebollar-Campos Mdel R, et al: Prevalence of folate and vitamin B12 deficiency in Mexican children aged 1 to 6 years in a population-based survey. Salud Publica Mex 2012;54:116-124.

47 Thomson BM, Vannoort RW, Haslemore RM: Dietary exposure and trends of exposure to nutrient elements iodine, iron, selenium and sodium from the 2003-4 New Zealand total diet survey. Br J Nutr 2008;99: 614-625.

48 International Zinc Nutrition Consultative Group (IZiNCG), Brown KH, Rivera JA, Bhutta Z, Gibson RS, King JC, Lönnerdal B, et al; International Zinc Nutrition Consultative Group (IZiNCG): Assessment of the risk of zinc deficiency in populations and options for its control. Food Nutr Bull 2004;25(1 suppl 2): S99-S203.

49 Rahmawaty S, Charlton K, Lyons-Wall P, Meyer BJ: Dietary intake and food sources of EPA, DPA and DHA in Australian children. Lipids 2013;48:869-877.

50 Ervin RB, Wright JD, Wang CY, KennedyStephenson J: Dietary intake of fats and fatty acids for the United States population: 19992000. Adv Data 2004;348:1-6.
51 Yakes EA: Polyunsaturated Fatty Acid Intake and Status of Breast Fed and Non-Breast Fed Bangladeshi Children 24-47 Months of Age. Davis, University of California, 2010.

52 Prentice AM, Paul AA: Fat and energy needs of children in developing countries. Am J Clin Nutr 2000;72(5 suppl):1253S-1265S.

53 Dewey KG: The challenge of meeting nutrient needs of infants and young children during the period of complementary feeding: an evolutionary perspective. J Nutr 2013;143:20502054.

54 Koletzko B, von Kries R, Closa R, Escribano J, Scaglioni S, Giovannini M, et al; European Childhood Obesity Trial Study Group: Lower protein in infant formula is associated with lower weight up to age $2 \mathrm{y}$ : a randomized clinical trial. Am J Clin Nutr 2009;89: 1836-1845.

55 Weber M, Grote V, Closa-Monasterolo R, Escribano J, Langhendries JP, Dain E, et al; European Childhood Obesity Trial Study Group: Lower protein content in infant formula reduces BMI and obesity risk at school age: follow-up of a randomized trial. Am J Clin Nutr 2014;99:1041-1051.

56 Hörnell A, Lagström H, Lande B, Thorsdottir I: Protein intake from 0 to 18 years of age and its relation to health: a systematic literature review for the 5th Nordic nutrition recommendations. Food Nutr Res 2013;57: 21083.

57 Mozaffarian D, Aro A, Willett WC: Health effects of trans-fatty acids: experimental and observational evidence. Eur J Clin Nutr 2009; 63(suppl 2):S5-S21.

58 Uauy R, Aro A, Clarke R, Ghafoorunissa, L'Abbé MR, Mozaffarian D, et al: WHO scientific update on trans fatty acids: summary and conclusions. Eur J Clin Nutr 2009;63(suppl 2): S68-S75.

59 World Health Organization: Guidelines: Sugars Intake for Adults and Children. Geneva, World Health Organization, 2015. 